Цедилкин и др. // Фундаментальные проблемы современного материаловедения. - 2011.
- № 4. - C. 125-130.

УДК 547.822.6 : 547.564.12:691.175.743

Черниговская Марина Алексеевна, к.т.н., дочент кафедры «Химическая технология топлива», ФГБОУ ВО «Ангарский государственный технический университет, e-mail: pm888@mail.ru

Семёнов Иван Александрович,

к.т.н., доиент кафедры «Химическая технология топлива» ФГБОУ ВО «Ангарский государственный технический университет», тел. 8(3955)51-29-03, e-mail: semenov_ia82@mail.ru

ОЦЕНКА ВОЗМОЖНОСТИ РАБОТЫ БЛОКА СИНТЕЗА МЕТАНОЛА-СЫРЦА С НИЗКОТЕМПЕРАТУРНЫМ КАТАЛИЗАТОРОМ

Chernigovskaya M.A., Semenov I.A.

\title{
ESTIMATION OF THE POSSIBILITY OF TRANSITION OF THE FACILITY FOR METHANOL SYNTHESYS TO WORK WITH LOW-TEMPERATURE CATALYSTS
}

Аннотация. В ходе исследования выполнено моделирование работы блока синтеза метанола-сырия в условиях замены катализатора. Модель прочесса составлена с применением программного пакета DWSim. На основании проведенных расчетов была оценена возможность работы блока синтеза метанола при высоком давлении с низкотемпературным катализатором.

Ключевые слова: метанол, моделирование, катализаторы.

Abstract. In the investigation, the modeling of the facility for the methanol synthesis was carried out under the conditions of the replacement of the catalyst. The process model was compiled using the DWSim software package. Based on the calculations, the possibility of working the highpressure methanol plant with a low-temperature catalyst was evaluated.

Keywords: methanol, modeling, catalysts.

Метанол - это первый и самый распространенный представитель гомологического ряда одноатомных спиртов. Он обладает хорошей реакционной способностью, что позволяет применять его в качестве реагента для многих процессов органического синтеза, а также рассматривать его в качестве топлива $[1,2]$.

На мировом рынке в течение последних лет наблюдается тенденция к росту спроса на метанол [3]. Подобная ситуация диктует потребности в создании новых мощностей по его производству, а также реконструкции и модернизации действующих установок.

Одним из способов сокращения затрат на производство метанола является использование более селективных медьсодержащих катализаторов. С учетом того, что процесс синтеза метанола на данных катализаторах отличается более высокой селективностью и протекает в более мягких условиях, это открывает новые возможности в использовании имеющихся мощностей по его производству, a также снижает затраты, что подтверждает актуальность данного исследования.

Целью данной работы является оценка возможности работы установки синтеза метанола при высоком давлении с низкотемпературным медьсодержащим катализатором. Для достижения поставленной цели необходимо решить следующие задачи:

1. Произвести расчет процесса синтеза метанола на медьсодержащем катализатоpe;

2. Сравнить результаты, полученные для процессов синтеза метанола на цинкхромовом и медьсодержащем катализаторе;

3. Дать заключение о принципиальной возможности использования медьсодержащего катализатора для производства метанола.

Для проведения исследования использовалась модель блока синтеза метаноласырца, описанная в работе [4]. Модель была сформирована на основе данных, полученных с действующей установки производства метанола при давлении 30 МПа и температу- 
pe $280-400{ }^{\circ} \mathrm{C}$. В качестве катализатора этой установки использовался высокотемпературный цинк-хромовый катализатор СMC-4, который широко используют для синтеза метанола.

Базовая модель процесса включала в себя такие стадии, как:

- смешение свежего и циркуляционного газа;

- нагрев основного потока в системе теплообменников Т-1 и печи П-1;
- химическое взаимодействие компонентов сырья в реакторе Р-1;

- охлаждение и конденсация газопродуктовой смеси в системе теплообменников;

- выделение метанола-сырца в системе сепараторов С-1 и С-2;

- компримирование циркуляционного газа, очистка и возврат его в процесс.

Схема модели, выполненная в пакете DWSim, представлена на рисунке 1.

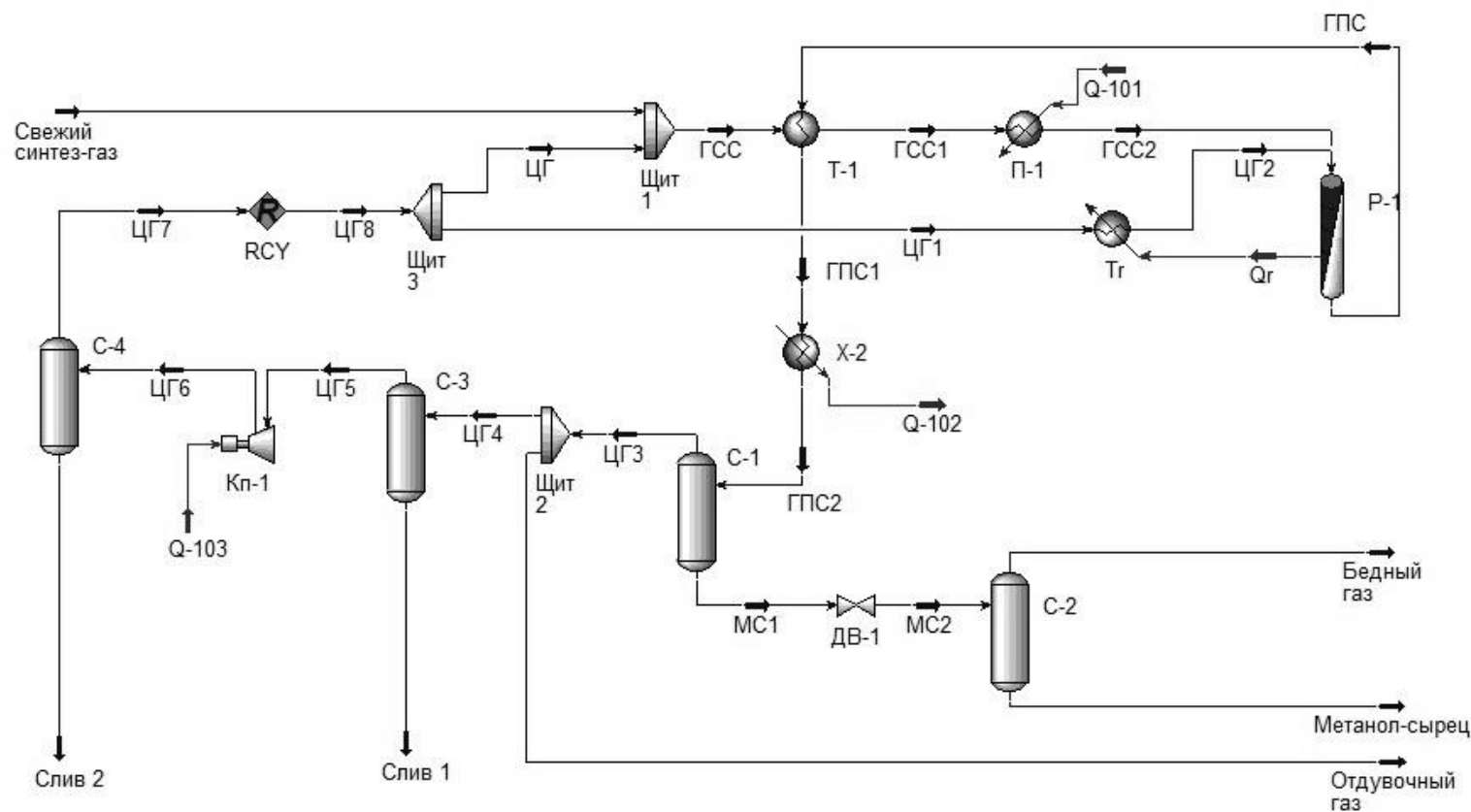

Рисунок 1 - Схема установки производства метанола в пакете DWSim:

ДВ-1 - щит дросселирования, Кп-1 - компрессор, П-1 - печь, Р-1 - реактор синтеза, С-1 - сепаратор высокого давления, С-2 - сепаратор низкого давления, C-3, C-4 - сепараторыкаплеотделители, Т-1 - теплообменник, $\mathrm{Tr}$ - оператор нагрева холодного газа в реакторе, X-2 холодильник, Щит 1 - щит смешения холодного газа, Щит 2 - щит сдувочного газа, Щит 3 щит циркуляционного газа, RCY - оператор рецикла, ГСС, ГПС - газосырьевая и газопродуктовая смесь, ЦГ - циркулирующий газ, МС - метанол-сырец

Для данного исследования был выбран катализатор МК-101 (Haldor Topsoe). Он представляет собой смесь оксидов цинка и меди на носителе из оксида алюминия и графита. Он используется в диапазоне температур синтеза от 205 до $310^{\circ} \mathrm{C}$, при рабочем давлении системы - 4-12 МПа, при этом суммарная степень конверсии сырья в зависимости от условий может достигать $90 \%$ [5, 6].

Согласно литературным данным [5, 6], на данном катализаторе протекают следующие основные реакции:

$$
\begin{gathered}
\mathrm{CO}+2 \mathrm{H}_{2} \rightleftharpoons \mathrm{CH}_{3} \mathrm{OH} \\
\mathrm{CO}_{2}+3 \mathrm{H}_{2} \rightleftharpoons \mathrm{CH}_{3} \mathrm{OH}+\mathrm{H}_{2} \mathrm{O}
\end{gathered}
$$

$$
\mathrm{CO}_{2}+\mathrm{H}_{2} \rightleftharpoons \mathrm{CO}+\mathrm{H}_{2} \mathrm{O}
$$

Данные по кинетике процесса были приняты на основании [7].

В качестве исходных условий для моделирования были приняты температура газа на входе в реактор $-230{ }^{\circ} \mathrm{C}$, давление в системе - 7 МПа. Состав свежего синтез-газа и соотношение потоков на щитах были приняты такими же, что и для модели процесса при высоком давлении.

В результате моделирования были получены данные о составах и количестве основных технологических потоков установки. Данные расчета представлены в таблице 1 .

Исследование показало, что содержание серы в составе сырья и рециркулирую- 
щего газа находится на достаточно низком


пользовать низкотемпературный катализатор без создания дополнительных стадий очистки сырьевых потоков, т.е. дает возможность проводить процесс на действующем оборудовании.

Таблица 1 - Сравнение основных параметров процесса синтеза метанола для разных катализаторов

\begin{tabular}{|l|c|c|}
\hline \multicolumn{1}{|c|}{ Параметр } & \multicolumn{2}{|c|}{ Катализатор } \\
\cline { 2 - 3 } & СМС-4 & МК-101 \\
\hline $\begin{array}{l}\text { Температура в реак- } \\
\text { торе, }{ }^{\circ} \text { : }\end{array}$ & $270-330$ & $230-250$ \\
\hline $\begin{array}{l}\text { Давление в реакторе, } \\
\text { МПа }\end{array}$ & 30 & 7 \\
\hline $\begin{array}{l}\text { Состав метанола- } \\
\text { сырца на выходе с ус- } \\
\text { тановки, мол. дол.: }\end{array}$ & 0,0003 & 0,0003 \\
\hline & 0,0004 & 0,0001 \\
\hline & - & 0,0008 \\
\hline СО & - & 0,0147 \\
\hline СО $_{2}$ & 0,1038 & 0,0225 \\
\hline $\mathrm{H}_{2} О$ & 0,8939 & 0,9615 \\
\hline $\mathrm{CH}_{3}$ ОН & 0,0015 & - \\
\hline $\mathrm{C}_{2} \mathrm{H}_{6} О$ & & \\
\hline Расход, кг/ч: $_{2 \text { метанола-сырца }}^{4904,68}$ & 1965,70 \\
\hline циркуляционного газа & 7252,86 & 48240,88 \\
\hline отдувочного газа & 503,611 & 3350,043 \\
\hline
\end{tabular}

Однако при сравнении параметров потоков при разных катализаторах было выявлено, что метанол, получаемый при низком давлении, имеет более высокую степень чистоты, однако его расход меньше, чем при высокотемпературном синтезе. Это свидетельствует о том, что несмотря на достаточно вы- сокую селективность, процесс синтеза метанола при низком давлении характеризуется более низкой степенью конверсии по сравнению с высокотемпературным процессом.

При этом, как следствие, увеличивается расход отдувочного и циркуляционного газа, что свидетельствует о повышении нагрузки на действующее оборудование.

В ходе проведенного моделирования процесса синтеза метанола на различных катализаторах были получены следующие результаты и выводы:

1. Получена базовая инженерная модель для производства метанола на катализаторе МК-101. Она составлена для условий действующего производства и на базе существующего оборудования. Модель является адекватной.

2. Применение полученной инженерной модели позволит в дальнейшем планировать работу производства, подбирать оптимальный технологический режим для производства продукции заданного объема и качества.

3. Проведенное сравнение полученных моделей показало, что при производстве метанола на катализаторе МК-101 увеличивается чистота получаемого метанола-сырца, однако снижается его выход в отличие от производства метанола на катализаторе СMC-4.

Снижение выхода метанола-сырца при производстве его на катализаторе МК-101 приводит к повышенной нагрузке на вспомогательное оборудование, следовательно, для сохранения уровня производительности установки потребуется замена части действующего оборудования на более производительное и эффективное.

\section{СПИСОК ЛИТЕРАТУРЫ}

1. Shcheklein, S. Hydrogen-methanol SOFCs for transport / S. Shcheklein, A. Dubinin // International Journal of Hydrogen Energy. 2021. - Vol. 46. - Issue 51. - pp. 25871-25877.

2. Акишин, Д. Газохимия России. Часть 1. Метанол: пока только планы. / Д. Акишин, А. Мамаков, А. Коровяков, М. Стацура - Текст : электронный // VYGON Consulting [сайт]. - 2021. - URL: https://vygon.consulting/products/issue-1544/ (дата обращения 06.2021).

3. Метанол 2018. - Текст : электронный // Creon conferences [сайт]. - 2021. URL: conferences.com/consulting/detailConf.php?ID=123802 (дата обращения 02.2020).

4. Данилов, С. А. Моделирование работы блока синтеза метанола на высокотемпературных катализаторах / С. А. Данилов, М. А. Черниговская, И. А. Семёнов // Вестник Ангарского государственного технического университета. - 2020. - № 14. - С. 3941.

5. Патент № 1838289 СССР, МПК С 07 С 31/04, 29/15, 27/06. Способ получения метанола : № 4894930/04 / заявл. 19.03.1990 : опубл. 18.03.1991 / Топсёе Х. Ф. А., Хансен 